expressions of standardising drug dose and used the ratio of prescribed dose over maximum BNF dose (i.e. 1.0 being maximum and $\mathbf{0}$ minimum) allowing addition of these units for polypharmacy within individual patients, with greater than 1.0 units being above BNF limits (C. Thompson, personal communication). We believe this 'ratio of maximum equivalent' has face validity in comparison with chlorpromazine equivalents since it avoids in particular the wide variation in chlorpromazine equivalence for high potency and low potency antipsychotics, though we are still exploring whether it provides a realistic alternative to chlorpromazine equivalents in the long term.

JOHN Milton, JOHN LAWTON, and ANN BUCKLEY, Nottingham Healthcare NHS Trust, Duncan Macmillan House, Porchester Road. Nottingham NG3 6AA

\section{The use of clozapine}

Sir: Regarding the use of clozapine (Drs Seabourne and Thomas and $\mathrm{Dr}$ Launer Psychiatric Bulletin. May 1995, 19, 326-327), the essential question is how to arrive at the optimum dose of clozapine to ensure response while minimising side-effects. As the steadystate plasma clozapine concentration can vary more than 45 fold on the same oral dose of clozapine (Potkin et al, 1994), a way of predicting likely clinical response would be useful.

Potkin et al (1994) have reported a fixeddose, double blind trial which demonstrated that a plasma concentration of $420 \mathrm{ng} / \mathrm{ml}$ distinguished responders from non-responders. After four weeks only $8 \%$ of those patients with a plasma clozapine concentration $<420 \mathrm{ng} / \mathrm{ml}$ responded, compared to $60 \%$ of those who had a plasma clozapine concentration $>420 \mathrm{ng} / \mathrm{ml}$. When plasma concentrations were increased above $420 \mathrm{ng} / \mathrm{ml}$ in the non-responders with low plasma clozapine levels (by a double-blind random assignment procedure), their response rate increased to $73 \%$ at 12 weeks compared to a response rate of only $29 \%$ if week 12 plasma levels remained below $420 \mathrm{ng} /$ ml. Further, no statistically significant differences in extrapyramidal symptom scores or abnormal movement scale were observed between patients with plasma levels above or below $420 \mathrm{ng} / \mathrm{ml}$.
Several other groups of investigators have now confirmed that clozapine plasma levels in the $350-420 \mathrm{ng} / \mathrm{ml}$ range are a threshold that can predict clinical response.

KRONG, et al (1995) Plasma clozapine levels and clinical response for treatment-refractory schizophrenic patients. American Joumal of Psychiatry, 182, 179-182.

MnuER, D. D., et al (1994) Plasma clozapine concentration as a predictor of clinical response: A follow-up study. Joumal of Clinical Psychiatry, 86(9, suppl. B), 177-121.

POTKIN, S. G., et al (1994) Plasma clozapine concentrations predict clinical response in treatment-resistant schizophrenia. Journal of Clinical Psychiatry. B5(9. suppl. B), 133-136.

Amir H. Kalal and Steven G. Potkin, University of California at Irvine, UCIMC, Building 3, Rt. 88, 101 The City Drive South, Orange, CA 92668, USA

\section{Research by trainees}

Sir: The editorial on Research by Trainees by Owen et al (Psychiatric Bulletin, June 1995, 19, 337-340) is timely and important. I would like to share my experience of research performed by trainees in Australia. After passing the formal examination of the Royal Australia and New Zealand College, the trainee is expected to spend a year (as a senior registrar) preparing a dissertation. Many trainees undertake a research project for this dissertation. Aspects of the research system assist the trainee in this endeavour. Senior Registrars tend to be supra numerary, and are allocated to consultants who would meet their research and clinical needs. In some units, trainees could receive a small grant to facilitate research (in one unit the figure was A\$ 1000). Finally, each hospital had a research and an ethics committee. The project would have to be approved by both committees before commencement. The research committee comprised of local academics and served the purpose of ensuring that a project was methodologically sound, plausible and realistic; trainees find this very helpful. It is important to provide an environment where trainees can pursue research easily and effectively.

A. K. SHAH, West London Healthcare NHS Trust, John Conolly Wing, Uxbridge Road, Southall UB1 3EU 